\title{
MUTATIONS IN THE GENE FOR THE GRANULOCYTE COLONY-STIMULATING-FACTOR RECEPTOR IN PATIENTS WITH ACUTE MYELOID LEUKEMIA PRECEDED BY SEVERE CONGENITAL NEUTROPENIA
}

\author{
Fan Dong, M.D., Ph.D., Russell K. Brynes, M.D., Nicola Tidow, Ph.D., Karl Welte, M.D., Ph.D., \\ Bob Löwenberg, M.D., Ph.D., And Ivo P. Touw, Ph.D.
}

\begin{abstract}
Background. In severe congenital neutropenia the maturation of myeloid progenitor cells is arrested. The myelodysplastic syndrome and acute myeloid leukemia develop in some patients with severe congenital neutropenia. Abnormalities in the signal-transduction pathways for granulocyte colony-stimulating factor (G-CSF) may play a part in the progression to acute myeloid leukemia.

Methods. We isolated genomic DNA and RNA from hematopoietic cells obtained from two patients with acute myeloid leukemia and histories of severe congenital neutropenia. The nucleotide sequences encoding the cytoplasmic domain of the G-CSF receptor were amplified by means of the polymerase chain reaction and sequenced. Murine myeloid 32D.C10 cells were transfected with complementary DNA encoding the wild-type or mutant G-CSF receptors and tested for their responses to G-CSF.

Results. Point mutations in the gene for the G-CSF receptor were identified in both patients. The mutations, a substitution of thymine for cytosine at the codon for
\end{abstract}

SEVERE congenital neutropenia (Kostmann's syn$S$ drome) comprises a heterogeneous group of disorders with variable inheritance whose main features are recurrent bacterial infections and severe neutropenia (fewer than 200 neutrophils per cubic millimeter). The bone marrow almost invariably shows an arrest of granulocytic maturation at the promyelocytic or myelocytic stage..$^{1-6}$ Patients with severe congenital neutropenia have an increased susceptibility to acute myeloid leukemia. ${ }^{7-10}$

An abnormal response of granulocytic progenitor cells to granulocyte colony-stimulating factor (G-CSF) may play a part in the pathogenesis of severe congenital neutropenia. The in vitro response to G-CSF of myeloid progenitor cells from patients with this disorder is often reduced. ${ }^{11,12}$ Pharmacologic doses of G-CSF increase the neutrophil count in the majority of patients with severe congenital neutropenia. ${ }^{12-14}$

The G-CSF receptor, a single polypeptide containing 813 amino acids, ${ }^{15,16}$ transduces signals that regulate the proliferation, maturation, and survival of myeloid progenitor cells. ${ }^{17}$ The cytoplasmic region proximal to the membrane of the receptor transduces proliferative and survival signals, whereas the distal C-terminal region transduces maturation signals and suppresses the receptor's proliferative signals. ${ }^{18-20}$

A truncated G-CSF receptor, lacking the G-terminal

From the Department of Hematology, Dr. Daniel den Hoed Cancer Center and Institute of Hematology, Erasmus University, Rotterdam, the Netherlands (F.D., B.L., I.P.T.); the Department of Clinical Pathology, City of Hope National Medical Center, Duarte, Calif. (R.K.B.); and the Department of Pediatric Hematology and Oncology, Hannover Medical School, Hannover, Germany (N.T., K.W.). Address reprint requests to Dr. Touw at the Dr. Daniel den Hoed Cancer Center, P.O. Box 5201, 3008 AE Rotterdam, the Netherlands.

Supported by the Dutch Cancer Society. glutamine at position 718 (Gln718) in one patient and at the codon for glutamine at position 731 (Gln731) in the other, caused a truncation of the C-terminal cytoplasmic region of the receptor. Both mutant and wild-type genes for the G-CSF receptor were present in leukemic cells from the two patients. In one patient, the mutation was also found in the neutropenic stage, before the progression to acute myeloid leukemia. The 32D.C10 cells expressing mutant receptors had abnormally high proliferative responses but failed to mature when cultured in G-CSF. The mutant G-CSF receptors also interfered with terminal maturation mediated by the wild-type G-CSF receptor in the 32D.C10 cells that coexpressed the wildtype and mutant receptors.

Conclusions. Mutations in the gene for the G-CSF receptor that interrupt signals required for the maturation of myeloid cells are involved in the pathogenesis of severe congenital neutropenia and associated with the progression to acute myeloid leukemia. (N Engl J Med 1995;333: 487-93.)

maturation domain as a consequence of a point mutation, has recently been reported in a patient with severe congenital neutropenia. ${ }^{21}$ We report here on point mutations in the gene for the G-CSF receptor in two patients with acute myeloid leukemia and histories of severe congenital neutropenia. These mutations also truncate the C-terminal cytoplasmic region of the G-CSF receptor. The mutation in one of the patients was already present in the neutropenic phase that preceded the development of acute myeloid leukemia. Our results suggest that the development of acute myeloid leukemia in patients with severe congenital neutropenia may involve a disruption of the maturation-signaling function of the G-CSF receptor.

\section{Case Reports}

\section{Patient 1}

The clinical and laboratory features of Patient 1 have been described previously. ${ }^{9}$ In brief, severe congenital neutropenia was diagnosed in this boy when he was two years and nine months old. There was no family history of an increased susceptibility to infection. When the boy was 12 years old, when the infections became more frequent and severe, G-CSF therapy was initiated; the absolute neutrophil count increased to 6000 per cubic millimeter. Eight months later, while the patient was receiving G-CSF therapy, peripheralblood tests revealed approximately 30 percent blasts. Bone marrow studies consistently showed a predominance of myeloblasts. Analysis revealed a karyotype of $49, \mathrm{XY},+3,+\operatorname{der}(5), \mathrm{t}(1 ; 5)(\mathrm{q} 21 ; \mathrm{q} 21),+22$. The patient died seven months later.

\section{Patient 2}

Severe congenital neutropenia was diagnosed in Patient 2 during the first year of life, when he had severe mastoiditis. There was no family history of hematologic disorders or an increased frequency of infections. During the first 20 years of his life, he had frequent episodes of pneumonitis, otitis, tonsillitis, and severe gingivitis. At the age of 20 years, he was enrolled in a phase 1-2 study of G-CSF 
(Filgrastim) in Hannover, Germany. At that time, bone marrow studies revealed an arrest of myelopoiesis at the promyelocytic or myelocytic stage, with an absence of bands and segmented neutrophils. There were no signs of myelodysplasia, and the cellularity of the bone marrow was normal. Treatment with G-CSF ( $3 \mu \mathrm{g}$ per kilogram of body weight per day) increased the neutrophil count to a level above 2000 per cubic millimeter within two weeks. During the next two years, the neutrophil count was maintained at this level with the same dose of G-CSF, and the patient had no severe infections.

Two years after the start of G-CSF treatment, a routine bone marrow examination demonstrated monosomy 7 in the myeloid lineage, but there was no sign of dysplasia or leukemia. G-CSF treatment was immediately discontinued, but it was restarted two months later, at the patient's request, because of severe stomatitis. Eleven months later, the myelodysplastic syndrome (the subtype characterized by refractory anemia and an excess of blasts) and thrombocytopenia developed. After an additional eight months, the patient presented with acute myeloid leukemia (subtype Ml according to the French-American-British classification) and subsequently died.

\section{METHODS}

\section{Polymerase-Chain-Reaction Amplification}

Genomic DNA was isolated from different cellular sources, as described elsewhere. ${ }^{22}$ Total RNA was isolated from leukemic cells from Patient 2 by the method of Chomczynski and Sacchi. ${ }^{23}$ RNA was reverse-transcribed into complementary DNA (cDNA) with the use of the reverse transcriptase of Moloney murine leukemia virus (GIBCO-BRL, Breda, the Netherlands). Amplification with the polymerase chain reaction (PCR) was performed as previously described. ${ }^{21}$ The following primers were used: FW2, 5'TGTGATCATGGTGACTCGCTT3' (forward); FW3, 5'CTGCTGTTGTTAACCTGCCTC3' (forward); FW4, 5'CCAAGAGCAGTTTCCA $\overline{A C} \bar{C}$ AGGCC3' (forward); FWI16, 5'ACCCTTTGTGTTCCACCAGT3' (forward); RV1, 5'CAAGATCTAGTTTACAATACTGAAG3' (reverse); RV2, 5'GTAGATCTTAGTCATGGGCTTATGG3' (reverse); and RV3, 5'TCTCAGG $\bar{G}$ GAGATAGTGCCC3' (reverse). The underlined nucleotides indicate the introduced mismatches.

\section{Nucleotide Sequencing}

After electrophoresis on agarose gels, PCR fragments were purified with the Geneclean II kit (Bio 101, La Jolla, Calif.) and sequenced directly or after subcloning in the pBluescript vector (Stratagene, La Jolla, Calif.), with the use of the T7 Sequencing Kit (Pharmacia P-L Biochemicals, Milwaukee).

\section{Expression Vectors for G-CSF Receptor}

A cDNA encoding a truncated G-CSF receptor (mutant $\mathrm{DA}^{18}$ ) was cloned at the EcoRI restriction site of the pBabe-puro retroviral expression vector that contains a puromycin-resistance gene, ${ }^{24}$ giving rise to the pBabe-DA construct. To constitute the full-length cDNA encoding the truncated G-CSF receptors in the two patients, PCR fragments obtained from Patients 1 and 2 with primer sets FWI16RV1 and FW2-RV1, respectively, were inserted into the HincII restriction site of the pBluescript vector and then cleaved with Cfr10I and XhoI. The resulting CfrlOI and XhoI fragments were used to replace the Cfr10I-SalI fragment of the pBabe-DA construct, thus creating the pBabe- 1 and pBabe- 2 expression vectors for Patients 1 and 2 , respectively. The pLNCX expression vector containing the wildtype G-CSF receptor cDNA (pLNCX-WT) has been described previously. ${ }^{18}$

\section{Cell-Line and Gene Transfection}

A subline of the murine myeloid cell line 32D, ${ }^{25}$ called 32D.C10, was fully dependent on murine interleukin-3 for proliferation and was unresponsive to G-CSF. ${ }^{18}$ The 32D.C10 cells were maintained in RPMI medium supplemented with 10 percent fetal-calf serum and 10 $\mathrm{ng}$ of interleukin-3 per milliliter. The expression constructs pBabe-1, pBabe-2, and pLNCX-WT were linearized with $P v u \mathrm{I}$ and introduced into the 32D.C10 cells by electroporation. After 48 hours of incubation, cells were selected with puromycin ( $1 \mu \mathrm{g}$ per milliliter) or G418
(0.8 $\mathrm{mg}$ per milliliter) in semisolid culture medium containing 0.9 percent methylcellulose. Single colonies were subsequently expanded in liquid culture for further analyses.

\section{Antibodies to the G-CSF Receptor}

Antiserum was raised by immunizing rabbits with a fusion protein consisting of a 6-histidine-residue tag and G-CSF receptor containing the extracellular domain of the receptor from amino acid 17 to amino acid 345. A corresponding Bam HI fragment of the G-CSF receptor cDNA was inserted into the $B a m H I$ restriction site of the bacteria expressing vector pQE-10 (Qiagen, Düsseldorf, Germany). A purified immunoglobulin fraction was obtained by protein A Sepharose affinity chromatography.

\section{Western Blotting and Assays of Cell Proliferation}

Cell lysates were prepared as described elsewhere ${ }^{26}$ and analyzed by a standard method of Western blotting. Tritium-labeled-thymidine uptake and long-term cell proliferation in response to G-CSF were measured as described elsewhere. ${ }^{18}$

\section{Morphologic and Cytochemical Analyses}

Cells were spun onto glass slides, and the morphologic features were examined after May-Grünwald-Giemsa staining. Myeloperoxidase staining was performed as described elsewhere. ${ }^{27}$ In each case, at least 400 cells were examined for staining.

\section{RESUlts}

\section{Mutations in the Gene for the G-CSF Receptor}

The entire exon $17,{ }^{28}$ which encodes the 156 amino acids of the C-terminal cytoplasmic region, and part of intron 16 of the G-CSF-receptor gene were amplified by PCR from genomic DNA isolated from bone marrow cells obtained from Patient 1 with primers FWI16 and RV1. The PCR product was subcloned, and a pool of 18 clones was sequenced. This sequence contained a cytosine-to-thymine (C-to-T) transition at nucleotide 2390 of the G-CSF receptor cDNA $^{15}$ (Fig. 1A). Direct sequencing of PCR products confirmed the presence of the point mutation (data not shown). This mutation changes the CAA codon for glutamine at position 718 (Gln718) to the TAA stop codon, thus truncating a C-terminal region of 96 amino acids, including the conserved box-3 segment of the receptor's cytoplasmic domain $^{30}$ (Fig. 1B).

Enzyme-restriction analysis was used to confirm the sequencing data and to examine the ratio of mutantto-normal genes for the G-CSF receptor in bone marrow cells from Patient 1. A single mismatch was introduced in primer FW4; it created a $S t u \mathrm{I}$ restriction site in the PCR product if the point mutation was present in the DNA (Fig. 2A). Analysis of eight individual clones showed that five contained the mutation (Fig. 2B). StuI digestion of the PCR product obtained from DNA of bone marrow cells collected at various times during the course of leukemia showed that the mutated gene made up a minor proportion of the DNA. The mutation was not detected in the liver or the spleen by StuI digestion and nucleotide sequencing (data not shown). These results indicate that the mutation did not occur in the germ line.

Only RNA samples were available from leukemic cells in peripheral blood obtained from Patient 2. Reverse-transcriptase PCR with primers FW2 and RV1 
Wild type 2384 CAG CCC CAA TCC CAG TCT GGC ACC AGC GAT CAG GTC CTT TAT GGG CAG CTG CTG 2437 Gln Pro Gln Ser Gln Ser Gly Thr Ser Asp Gln Val Leu Tyr Gly Gln Leu Leu 733

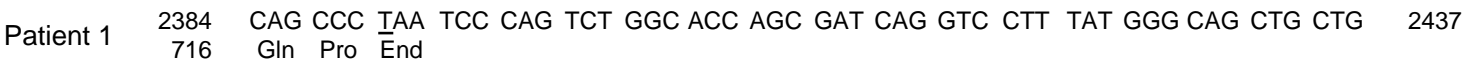

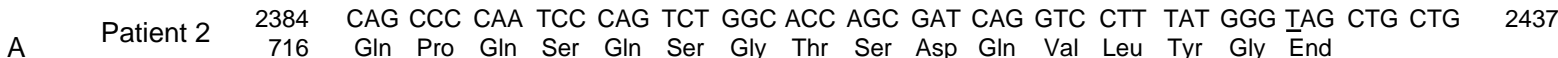
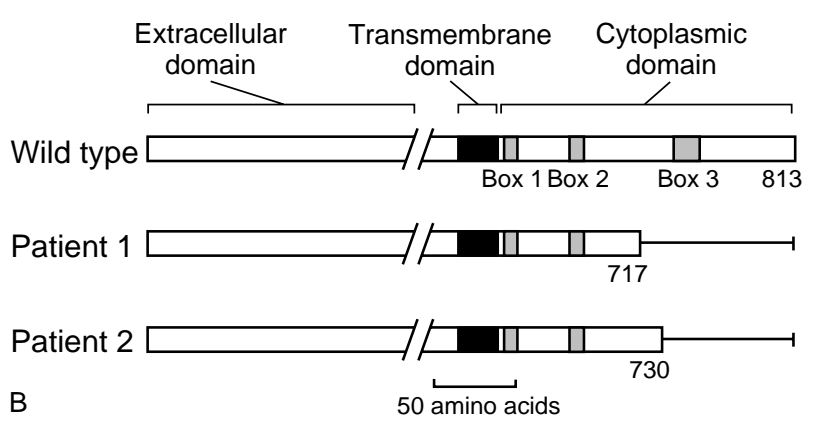

was used to amplify the entire transmembrane and cytoplasmic domains, as well as part of the extracellular domain, of the G-CSF-receptor cDNA. After subcloning of the PCR product, nucleotide sequencing was performed with a pool of 16 clones. A C-to-T point mutation was identified at nucleotide 2429 (Fig. 1A). This mutation, which changes the CAG codon for glutamine at position 731 (Gln731) to the TAG stop codon, deleted the 83 G-terminal amino acids of the G-CSF receptor (Fig. 1B). The mutation destroys a PvuII restriction site in the G-CSF receptor cDNA. PvuII digestion of PGR products obtained with primers FW3 and RV2 revealed transcripts of both the normal and mutated
Figure 1. Mutations in the Gene for the G-CSF Receptor in Patients 1 and 2.

Panel A shows the sequences flanking the point mutations and the wild-type sequence. The numbers indicate the nucleotide positions (upper numbers) and amino acid positions (lower numbers). The point mutations are underlined. Panel $B$ shows the structures of the wild-type and truncated G-CSF receptors. Boxes 1,2 , and 3 represent cytoplasmic subdomains conserved in several members of the hematopoietin-receptor superfamily. ${ }^{29}$ The horizontal lines in the cytoplasmic domains for Patients 1 and 2 indicate the $\mathrm{C}$-terminal regions that have been deleted because of the point mutations. The numbers denote amino acid positions.

G-CSF receptor alleles (Fig. 3). To determine whether the point mutation was present before acute myeloid leukemia developed in Patient 2, DNA was isolated from a bone marrow smear prepared when the patient was in the neutropenic phase, before the acquisition of monosomy 7. A minor proportion of the DNA contained the mutation (Fig. 3), indicating that it had arisen from a somatic event.

\section{Transduction of Proliferative and Maturation Signals by Wild-Type and Mutant G-CSF Receptors}

The function of the mutant G-CSF receptors from the two patients was tested in murine myeloid 32D.C10
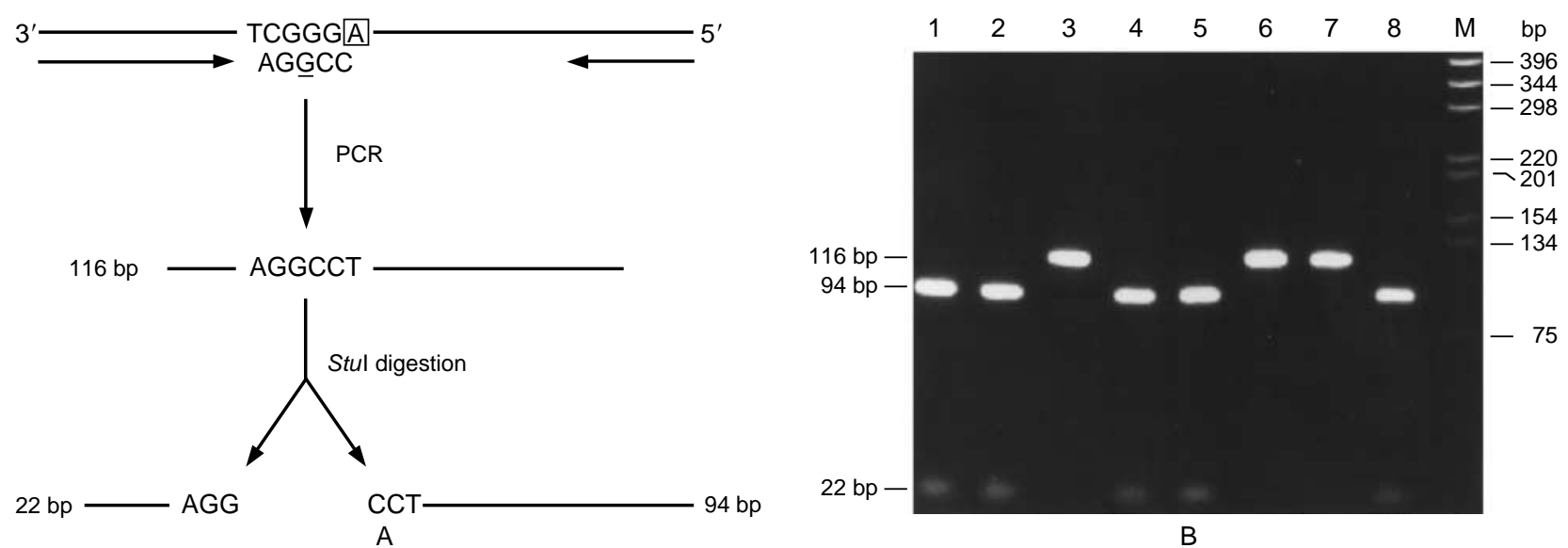

Figure 2. Stul Restriction-Enzyme Analysis of the PCR Product.

In Panel A, the point mutation in the template DNA (in the antisense orientation) is boxed. A mismatch (underlined) introduced in the forward primer, together with the point mutation in the template DNA, creates a Stul restriction site in the PCR product. The arrows indicate the direction of the primers. Panel B shows Stul digestion of individual clones of the PCR product obtained from leukemic cells from Patient 1. The nondigested product (116 base pairs [bp]) was derived from normal G-CSF-receptor sequences; the digested product (94 bp and $22 \mathrm{bp}$ ) was derived from the mutated allele. PCR products were separated on a 3 percent NuSieve agarose gel. $\mathrm{M}$ denotes the molecular-size markers. 
cells that were transfected with cDNA encoding the wild-type or mutated G-CSF receptors. The expression of the G-CSF-receptor proteins in the transfected 32D.C10 cells was examined by Western blot analysis. The wild-type G-CSF-receptor protein had an apparent molecular weight of 140,000 to 150,000 , whereas the mutant proteins from Patients 1 and 2 had a molecular weight of 115,000 to 135,000 and 120,000 to 140,000 , respectively (data not shown). These variations in molecular weight were probably due to differences in protein glycosylation. ${ }^{15}$

The capacities of the G-CSF receptors to transduce
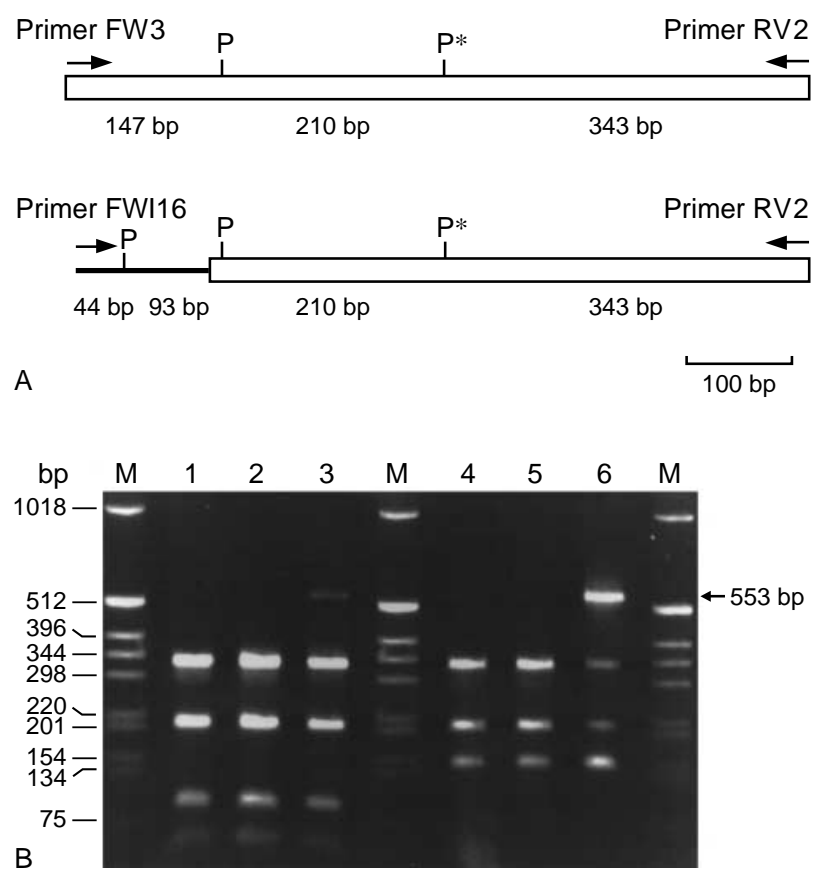

Figure 3. Pvull Restriction-Enzyme Analysis of PCR Products. Panel A shows the PCR products amplified from cDNA (top) and genomic DNA (bottom). The relative positions of the Pvull restriction sites and the expected sizes of the DNA fragments (in base pairs) after Pvull digestion are indicated. The PCR primers are also indicated. The open boxes denote the sequences derived from cDNA and exon 17; the sequence derived from intron 16 is shown as a bold line. The arrows indicate the direction of the primers. $P$ denotes the Pvull restriction site, and an asterisk indicates that the site was eliminated by the point mutation.

Panel B shows the detection of the point mutation by Pvull digestion of PCR products. Amplification was performed on genomic DNA prepared from bone marrow cells obtained from healthy persons (lanes 1 and 2) and from Patient 2 during the neutropenic phase (lane 3), as well as on RNA isolated from normal granulocytes in peripheral blood (lanes 4 and 5) and leukemic cells from Patient 2 (lane 6). PCR products were separated on a 2 percent NuSieve agarose gel. The 553-bp fragment (arrow) derived from the mutant G-CSF receptor is present in lane 3 (the neutropenic phase) and in lane 6 (the leukemic phase) but not in the lanes containing products from normal marrow. Partial digestion does not account for the results, since there was complete digestion of the other Pvull sites in the PCR products. $\mathrm{M}$ denotes the molecular-size markers. proliferative signals were analyzed in assays with tritium-labeled thymidine. The 32D.C10 cells expressing the wild-type receptor (32D.WT) had a dose-dependent response to G-CSF and proliferated most efficiently at the level of $3 \mathrm{ng}$ of G-CSF per milliliter, which is about 75 percent of the response to interleukin-3 (Fig. 4A). The 32D.C10 cells that expressed the mutant receptors from Patient 1 (32D.1) or Patient 2 (32D.2) had a considerably increased sensitivity to G-CSF, requiring concentrations of the factor that were approximately 10 times lower than the concentrations required by the 32D.WT cells for maximal proliferation. Unlike the cells transfected with the wild-type cDNA, the 32D.1 and 32D.2 cells had maximal responses to $\mathrm{G}-\mathrm{CSF}$ that were similar to the responses to interleukin-3 (Fig. 4A).

In long-term cultures, the 32D.WT cells proliferated transiently in medium containing G-CSF. The cells gradually lost viability after 4 to 6 days in the medium (Fig. 4B) and died after 12 to 14 days. In contrast, the 32D.1 and 32D.2 cells proliferated continuously and could be maintained in G-CSF-containing culture medium for at least one month.

When cultured in medium containing interleukin-3, the 32D.WT cells had morphologic features that were typical of those of immature myeloid cells, and 50 to 60 percent of the cells displayed weak myeloperoxidase staining. Despite the death of substantial numbers of cells after 8 to 12 days of culture in G-CSF-containing medium, the surviving 32D.WT cells exhibited morphologic features characteristic of terminal granulocytic maturation (Fig. 5A), and nearly all the cells showed strong myeloperoxidase staining. In striking contrast, G-CSF treatment of 32D.1 and 32D.2 cells induced neither morphologic changes indicative of granulocytic maturation nor an increase in the expression of myeloperoxidase protein as indicated by myeloperoxidase staining (data not shown).

\section{Effect of Mutant Receptors on Granulocytic Maturation Mediated by the Wild-Type G-CSF Receptor}

Because the leukemic cells from both patients expressed not only the mutated genes for the G-CSF receptor but also the normal alleles of the gene, we performed studies to determine whether the mutant receptors interfere with the function of the wild-type receptor. Two 32D.WT clones were transfected with pBabe-puro expression vector carrying the cDNAs of the mutant receptors from Patient 1 and Patient 2 or only empty pBabe-puro vector (the negative control). Expression of the wild-type and mutant G-CSF-receptor proteins in single clones was verified by Western blot analysis, and those that expressed approximately equal levels of the wild-type and mutant G-CSFreceptor proteins were examined. Transfection of 32D.WT cells with the empty vector did not alter G-CSF-induced proliferation and maturation (data not shown). The 32D.WT cells coexpressing the mu- 

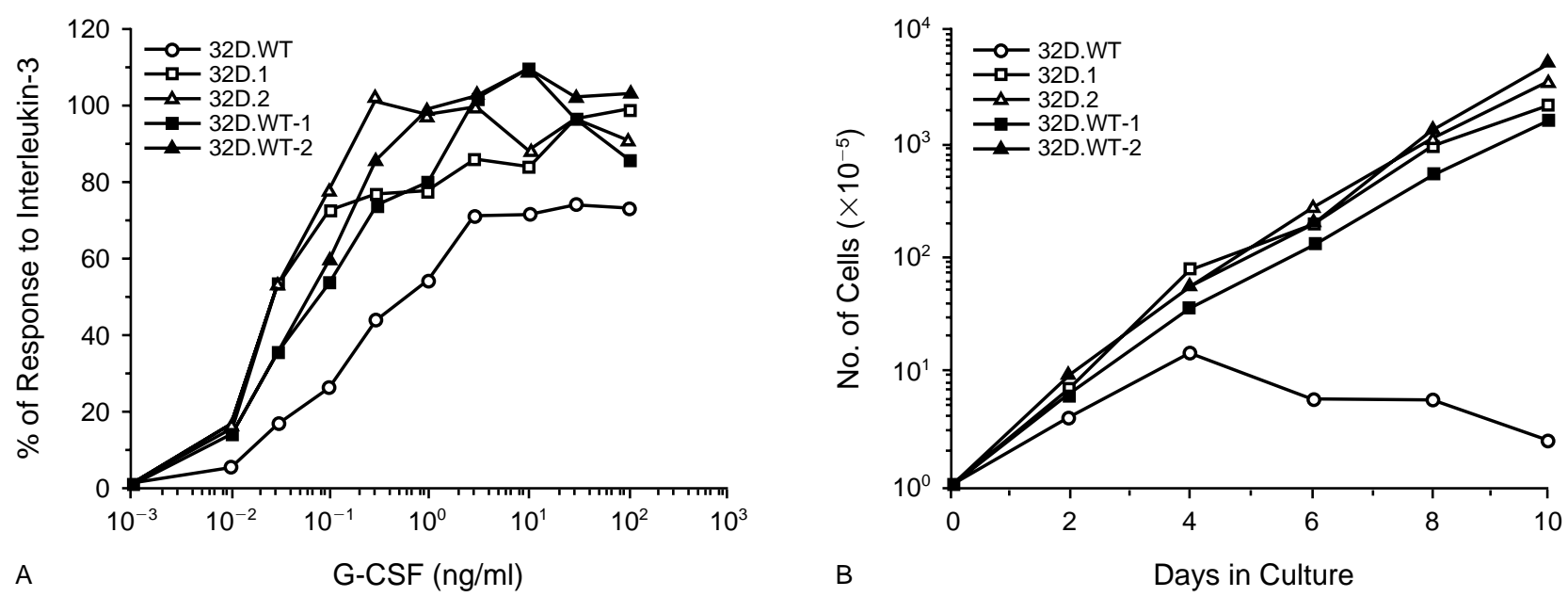

Figure 4. G-CSF-Induced Proliferative Responses of 32D.C10 Clones Expressing Various G-CSF Receptors.

Panel A shows the response to G-CSF in comparison with the response to interleukin-3. DNA synthesis was determined by the uptake of tritium-labeled thymidine. Data are presented as the percentage of the maximal response to 10 ng of murine interleukin-3 per milliliter for each clone. Analogous results were obtained with at least three independent clones for each form of receptor. Panel B shows the level of cell proliferation induced by G-CSF, according to the number of days in culture. Cells were cultured in medium containing $10 \mathrm{ng}$ of G-CSF per milliliter. The number of viable cells was determined on the basis of trypan-blue exclusion. 32D.WT denotes cells expressing the wild-type receptor, 32D.1 cells expressing the mutant receptor from Patient 1, 32D.2 cells expressing the mutant receptor from Patient 2, 32D.WT-1 cells expressing the wild-type receptor and mutant receptor from Patient 1, and 32D.WT-2 cells expressing the wild-type receptor and mutant receptor from Patient 2.

tant receptor from Patient 1 (32D.WT-1) or Patient 2 (32D.WT-2) had increased proliferative responses to G-CSF (Fig. 4A) and proliferated continuously in culture medium containing G-CSF alone (Fig. 4B). Both the 32D.WT-1 cells and the 32D.WT-2 cells were unable to mature terminally in response to G-CSF (Fig. $5 \mathrm{~B}$ and $5 \mathrm{C}$ ). In fact, the responses of the 32D.WT-1 cells and the 32D.WT-2 cells to G-CSF were indistinguishable from the response of the 32D.1 and 32D.2 cells.

\section{Discussion}

In this study, we have detected point mutations in the gene for the G-CSF receptor in two patients with acute myeloid leukemia and histories of severe congenital neutropenia. The mutations truncate the C-terminal cytoplasmic region of the receptor that participates in the transduction of maturation signals. ${ }^{18,19}$ In one patient the mutation was already present in the neutropenic phase, before the progression to acute myeloid leukemia. When expressed in murine 32D.C10 cells, the truncated G-CSF receptors from the two patients transduced stronger proliferative signals than the wildtype receptor but were defective in inducing maturation. Moreover, the mutant receptors blocked granulocytic maturation even in the presence of wild-type G-CSF receptors, presumably by forming heterodimers with the wild-type receptors. ${ }^{31,32}$ Taken together, our data suggest that disruption of the maturation-signaling function of the G-CSF receptor contributes to leukemogenesis.

Not all patients with severe congenital neutropenia have mutations in the G-CSF receptor. ${ }^{21,33,34}$ No such mutations corresponding to the cytoplasmic domain were found in three patients with severe congenital neutropenia who were members of the Swedish families in which the disease was originally described (unpublished data). However, a point mutation in the gene for the G-CSF receptor, causing truncation of the C-terminal region, has been identified in a patient with severe congenital neutropenia and monosomy 7 but no signs of the myelodysplastic syndrome or acute myeloid leukemia (unpublished data). The mutation was detected in myeloid cells from this patient but not in B lymphocytes, indicating its acquisition by a committed progenitor cell. Thus far, we have found mutations in the gene for the G-CSF receptor in 4 of 14 patients with severe congenital neutropenia; in all 4 , the mutation truncated the G-terminal region. Patients with severe congenital neutropenia and such truncated receptors may represent a subgroup of patients in whom the neutropenia is a preleukemic disorder.

Recombinant human G-CSF, now used frequently in the treatment of severe congenital neutropenia, ${ }^{12-14}$ can have favorable results. However, acute myeloid leukemia or the myelodysplastic syndrome has developed after the administration of G-CSF in patients with severe congenital neutropenia. ${ }^{35-37}$ It remains uncertain whether G-CSF therapy contributes to the progression to acute myeloid leukemia in such patients. Analysis of the G-CSF receptor in a large series of patients with severe congenital neutropenia will help elucidate the relation among defective G-CSF-receptor structures, the progression to acute myeloid leukemia, 


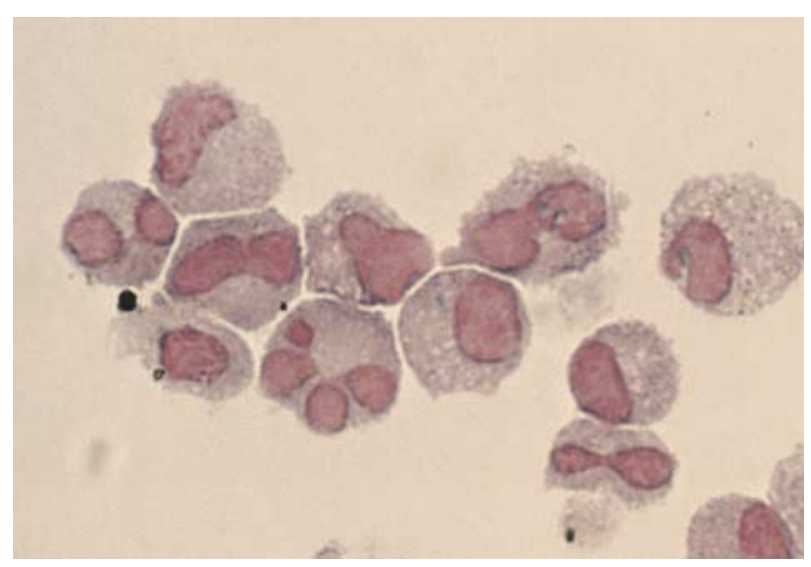

A

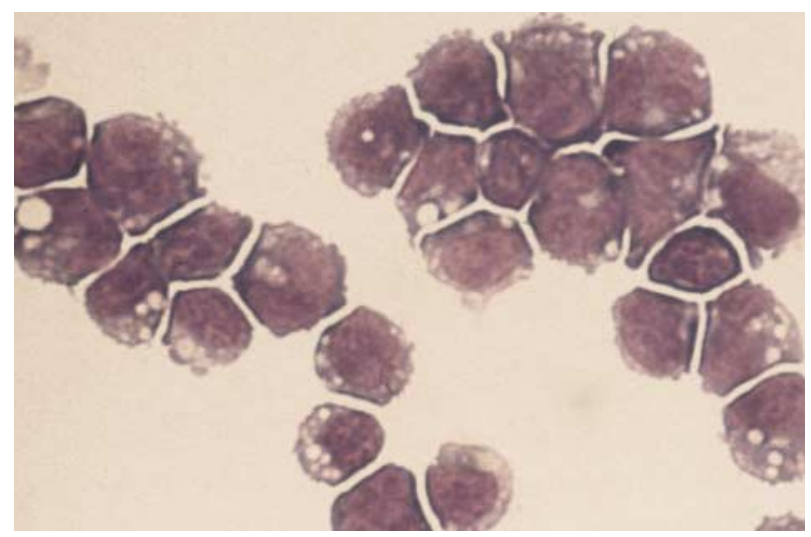

B

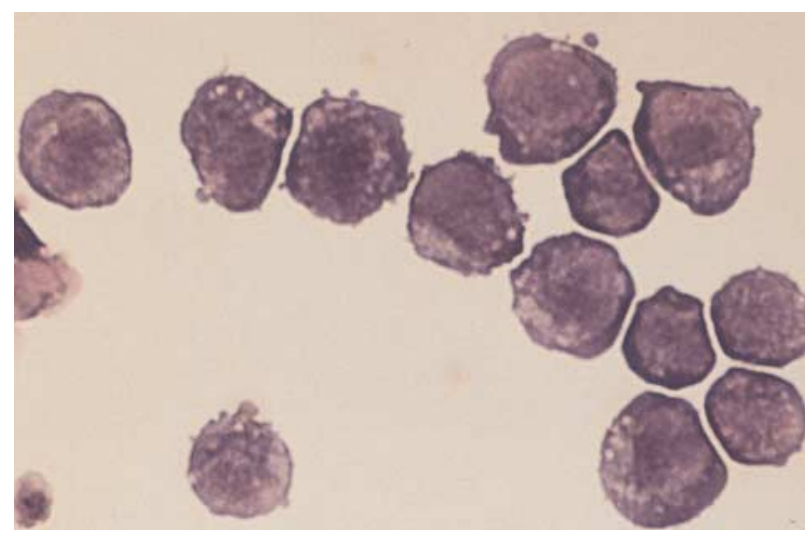

C

Figure 5. Morphologic Features of 32D.C10 Clones Expressing Wild-Type and Mutant G-CSF Receptors (May-Grünwald-Giemsa Stain, $\times 630)$.

The cells were cultured for 10 days in medium containing G-CSF (10 ng per milliliter). Panel A shows cells expressing the wildtype receptor (32D.WT), Panel B cells expressing the wild-type receptor and the mutant receptor from Patient 1 (32D.WT-1), and Panel $\mathrm{C}$ cells expressing the wild-type receptor and the mutant receptor from Patient 2 (32D.WT-2). The 32D.WT cells matured into neutrophilic granulocytes in response to G-CSF, whereas the 32D.WT-1 and 32D.WT-2 cells retained a myeloblastic appearance. and the contribution of G-CSF therapy to leukemogenesis.

We are indebted to Anita Schelen, Marleen van Paassen, and Birgit Teichmann for excellent technical assistance; and to Dr. Hartmut Land (Imperial Cancer Research Fund, London) for the pBabe-puro expression vector.

\section{REFERENCES}

1. Kostmann R. Infantile genetic agranulocytosis: a new recessive lethal disease in man. Acta Paediatr 1956;Suppl 105:1-78.

2. Wriedt K, Kauder E, Mauer AM. Defective myelopoiesis in congenital neutropenia. N Engl J Med 1970;283:1072-7.

3. Rodin AE, Haggard ME, Nichols MM, Gustavson LP. Infantile genetic agranulocytosis: two cases occurring in siblings and one in a distant relative. Am J Dis Child 1973;126:818-21.

4. Kostmann R. Infantile genetic agranulocytosis: a review with presentation of ten new cases. Acta Paediatr Scand 1975;64:362-8.

5. Amato D, Freedman MH, Saunders EF. Granulopoiesis in severe congenital neutropenia. Blood 1976;47:531-8.

6. Kawaguchi Y, Kobayashi M, Tanabe A, et al. Granulopoiesis in patients with congenital neutropenia. Am J Hematol 1985;20:223-34.

7. Gilman PA, Jackson DP, Guild HG. Congenital agranulocytosis: prolonged survival and terminal acute leukemia. Blood 1970;36:576-85.

8. Rosen RB, Kang S-J. Congenital agranulocytosis terminating in acute myelomonocytic leukemia. J Pediatr 1979;94:406-8.

9. Wong W-Y, Williams D, Slovak ML, et al. Terminal acute myelogenous leukemia in a patient with congenital agranulocytosis. Am J Hematol 1993;43: 133-8.

10. Gillio AP, Gabrilove JL. Cytokine treatment of inherited bone marrow failure syndromes. Blood 1993;81:1669-74.

11. Kobayashi M, Yumiba C, Kawaguchi Y, et al. Abnormal responses of myeloid progenitor cells to recombinant human colony-stimulating factors in congenital neutropenia. Blood 1990;75:2143-9.

12. Welte K, Zeidler C, Reiter A, et al. Differential effects of granulocyte-macrophage colony-stimulating factor and granulocyte colony-stimulating factor in children with severe congenital neutropenia. Blood 1990;75:1056-63.

13. Bonilla MA, Gillio AP, Ruggeiro M, et al. Effects of recombinant human granulocyte colony-stimulating factor on neutropenia in patients with congenital agranulocytosis. N Engl J Med 1989;320:1574-80.

14. Dale DC, Bonilla MA, Davis MW, et al. A randomized controlled phase III trial of recombinant human granulocyte colony-stimulating factor (filgrastim) for treatment of severe chronic neutropenia. Blood 1993;81:2496-502.

15. Fukunaga R, Seto Y, Mizushima S, Nagata S. Three different mRNAs encoding human granulocyte colony-stimulating factor receptor. Proc Natl Acad Sci U S A 1990;87:8702-6.

16. Larsen A, Davis T, Curtis BM, et al. Expression cloning of a human granulocyte colony-stimulating factor receptor: a structural mosaic of hematopoietin receptor: immunoglobulin, and fibronectin domains. J Exp Med 1990; 172:1559-70.

17. Demetri GD, Griffin JD. Granulocyte colony-stimulating factor and its receptor. Blood 1991;78:2791-808

18. Dong F, van Buitenen C, Pouwels K, Hoefsloot LH, Löwenberg B, Touw IP. Distinct cytoplasmic regions of the human granulocyte colony-stimulating factor receptor involved in induction of proliferation and maturation. Mol Cell Biol 1993;13:7774-81.

19. Fukunaga R, Ishizaka-Ikeda E, Nagata S. Growth and differentiation signals mediated by different regions in the cytoplasmic domain of granulocyte colony-stimulating factor receptor. Cell 1993;74:1079-87.

20. Ziegler SF, Bird TA, Morella KK, Mosley B, Gearing DP, Baumann H. Distinct regions of the human granulocyte-colony-stimulating factor receptor cytoplasmic domain are required for proliferation and gene induction. Mol Cell Biol 1993;13:2384-90.

21. Dong F, Hoefsloot LH, Schelen AM, et al. Identification of a nonsense mutation in the granulocyte-colony-stimulating factor receptor in severe congenital neutropenia. Proc Natl Acad Sci U S A 1994;91:4480-4.

22. Miller SA, Dykes DD, Polesky HF. A simple salting out procedure for extracting DNA from human nucleated cells. Nucleic Acids Res 1988;16:1215.

23. Chomczynski P, Sacchi N. Single-step method of RNA isolation by acid guanidinium thiocyanate-phenol-chloroform extraction. Anal Biochem 1987; 162:156-9.

24. Morgenstern JP, Land H. Advanced mammalian gene transfer: high titre retroviral vectors with multiple drug selection markers and a complementary helper-free packaging cell line. Nucleic Acids Res 1990;18:3587-96.

25. Greenberger JS, Sakakeeny MA, Humphries RK, Eaves CJ, Eckner RJ. Demonstration of permanentfactor-dependent multipotential(erythroid/neutrophil/basophil) hematopoietic progenitor cell lines. Proc Natl Acad Sci U S A 1983;80:2931-5. 
26. Dong F, van Paassen M, van Buitenen C, Hoefsloot LH, Löwenberg B, Touw IP. A point mutation in the granulocyte colony-stimulating factor receptor (G-CSF-R) gene in a case of acute myeloid leukemia in the overexpression of a novel G-CSF-R isoform. Blood 1995;85:902-11.

27. Hayhoe FGJ, Flemans RJ. Hematological cytology. 3rd ed. London: Wolfe Publishing, 1992:378.

28. Seto Y, Fukunaga R, Nagata S. Chromosomal gene organization of the human granulocyte colony-stimulating factor receptor. J Immunol 1992;148:259-66.

29. Cosman D. The hematopoietin receptor superfamily. Cytokine 1993;5:95-106.

30. Fukunaga R, Ishizaka-Ikeda E, Pan C-X, Seto Y, Nagata S. Functional domains of the granulocyte colony-stimulating factor receptor. EMBO J 1991; 10:2855-65.

31. Heldin C-H. Dimerization of cell surface receptors in signal transduction. Cell 1995;80:213-23.

32. Hiraoka O, Anaguchi H, Ota Y. Evidence of the ligand-induced conversion from a dimer to a tetramer of the granulocyte colony-stimulating factor receptor. FEBS Lett 1994;356:255-60.
33. Guba SC, Boxer LA, Emerson SG. G-CSF receptor transmembrane and intracytosolic structure in patients with congenital neutropenia. Blood 1993; 82:Suppl 1:23a. abstract.

34. Sandoval C, Adams-Graves P, Parganas E, Wang W, Ihle JN. The cytoplasmic portion of the G-CSF receptor is normal in patients with Kostmann syndrome. Blood 1993;82:Suppl 1:185a. abstract.

35. Bonilla MA, Dale D, Zeidler C, et al. Long-term safety of treatment with recombinant human granulocyte colony-stimulating factor (r-metHuG-CSF) in patients with severe congenital neutropenias. Br J Haematol 1994;88:72330 .

36. Imashuku S, Hibi S, Kataoka-Morimoto Y, et al. Myelodysplasia and acute myeloid leukaemia in cases of aplastic anaemia and congenital neutropenia following G-CSF administration. Br J Haematol 1995;89:188-90.

37. Weinblatt ME, Scimeca P, James-Herry A, Sahdev I, Kochen J. Transformation of congenital neutropenia into monosomy 7 and acute nonlymphoblastic leukemia in a child treated with granulocyte colony-stimulating factor. $\mathrm{J} \mathrm{Pe}$ diatr 1995; 126:263-5. 